\title{
Integrating Palliative Medicine into Comprehensive Breast Cancer Therapy - a Pilot Project
}

\author{
Jan Gaertner ${ }^{a, b}$ Rachel Wuerstlein ${ }^{b, c} \quad$ Ursula Klein $^{a}$ Dennis Scheicht ${ }^{a}$ Sebastian Frechen ${ }^{a}$ \\ Jürgen Wolf ${ }^{\mathrm{b}, \mathrm{d}}$ Martin Hellmich ${ }^{\mathrm{e}}$ Peter Mallmann $^{\mathrm{b}, \mathrm{c}}$ Nadia Harbeck $^{\mathrm{b}, \mathrm{c}}$ Raymond Voltz ${ }^{\mathrm{a}, \mathrm{b}}$
}

${ }^{a}$ Department of Palliative Medicine, University Hospital, Cologne, ${ }^{b}$ Center for Integrated Oncology Cologne/Bonn, 'Department of Senology, dDepartment I of Internal Medicine, e Institute of Medical Statistics, Informatics and Epidemiology, University Hospital, Cologne, Germany

\section{Keywords}

Comprehensive cancer care - Palliative medicine .

Simultaneous care $\cdot$ Shared care $\cdot$ Quality of life .

Symptom control

\section{Summary}

Background: To comply with the World Health Organization (WHO) recommendations, our institution's administrative directives were adopted to advocate the provision of palliative care (PC) early in the disease trajectory of breast cancer (BC). To assess the outcome of this recommendation, this study evaluated the effects of this approach. Methods: A retrospective systematic chart analysis of a 2-year period was performed. The first PC consultation of patients was analyzed according to (a) physical condition, (b) symptom burden of the patients, and (c) reasons for PC consultation. Results: Many patients were already in a reduced physical state and experienced burdening symptoms when first counselled by PC. After a 1-year experience with PC consultations, the number of burdening symptoms identified at first PC consultation decreased and senologists increasingly requested PC support also for non-somatic issues. Conclusions: A development towards a better understanding of PC competencies after a 1-year initiation period could be demonstrated, but BC patients continued to be in late stages of the disease at the time of first PC contact. Disease-specific guidelines may facilitate and optimize the integration of PC into breast cancer therapy.

\author{
Schlüsselwörter \\ Umfassende Krebsbehandlung · Palliativmedizin . \\ Frühe Integration . Gemeinsame Versorgung • \\ Lebensqualität $\cdot$ Symptomkontrolle
}

\section{Zusammenfassung}

Hintergrund: Um den Empfehlungen der Weltgesundheitsorganisation (WHO) zu entsprechen, wurden die Leitlinien unserer Institution angepasst, um explizit die frühe Integration spezialisierter palliativmedizinischer Expertise in die Behandlung von Brustkrebspatienten zu empfehlen. Um den Effekt dieser Empfehlung zu beurteilen, wurden in dieser Studie die Auswirkungen dieses Ansatzes ausgewertet. Methoden: Es wurde eine systematische retrospektive Auswertung der Palliativkonsile aus den ersten 2 Jahren nach Einführung der Empfehlung früher palliativmedizinischer Integration durchgeführt. Der erste Kontakt einer Patientin (Erstkonsil) zur Palliativmedizin wurde untersucht hinsichtlich a) des Allgemeinzustands der Patientin, b) des Vorliegens belastender körperliche Symptome sowie c) der Gründe für die Konsultation. Ergebnisse: Viele Patientinnen waren beim Erstkonsil bereits in reduziertem Allgemeinzustand und litten unter belastenden körperlichen Symptomen. Nach 1-jähriger Erfahrung des senologischen Teams mit palliativmedizinischen Konzepten und Interventionen sank die Zahl der beim Erstkonsil identifizierten belastenden körperlichen Symptome und es wurden zunehmend palliativmedizinische Konsile explizit auch für psychosoziale Interventionen angefordert. Zusammenfassung: Nach einer 1-jährigen Anfangsphase nach der Empfehlung "früher Integration" konnte eine Entwicklung hin zu einem besseren Verständnis palliativmedizinischer Kompetenzen gezeigt werden. Die Brustkrebspatientinnen waren jedoch weiterhin beim palliativmedizinischen Erstkonsil bereits oft in einem weit fortgeschrittenen Stadium Ihrer Erkrankung. Krankheitsspezifische Leitlinien könnten die Integration palliativmedizinischer Betreuung in die Behandlung von Brustkrebspatienten erleichtern und optimieren.

\section{KARGER \\ Fax +497614520714 \\ Information@Karger.de}

www.karger.com
(C) 2011 S. Karger GmbH, Freiburg

$1661-3791 / 11 / 0063-0215 \$ 38.00 / 0$

Accessible online at:

www.karger.com/brc
Dr. Jan Gaertner

Department of Palliative Medicine

University Hospital Cologne

50924 Cologne, Germany

Tel. +49 221 478-3361, Fax -89300

jan.gaertner@uk-koeln.de 


\section{Introduction}

The early integration of palliative care (PC) in the disease trajectory of patients with life-limiting illness is explicitly recommended by the World Health Organization (WHO) [1]. The recommendation literally states that 'PC is applicable early in the course of illness, in conjunction with other therapies that are intended to prolong life, such as chemotherapy or radiation therapy' [1]. Yet, no further information as to how this could be accomplished is provided.

To support the 'early integration' of PC into (breast) cancer therapy, the WHO recommendation was included in the administrative directives for principles of cancer care and a PC hospital support team (PCST) following the European Commission recommendations [2] was set up in addition to the existing inpatient and specialized home care PC service.

A retrospective analysis of the first $\mathrm{PC}$ consultations provided for breast cancer (BC) patients was performed to evaluate whether this approach was adequate to successfully integrate PC into routine cancer therapy. The aim of the evaluation was to assess at which point in the disease trajectory integration of PC could be achieved. As indicators, we analyzed (i) performance status and (ii) symptoms as markers for advanced disease (e.g. dyspnea) [3, 4]. Assuming that acceptance of this new approach would increase over time, findings during the 1st and the 2nd year of the observation period were compared.

\section{Methods}

\section{Indicators for 'Early' Integration of PC}

The first consultation of the PCST was considered as the point of PC integration. The first PCST consultation for every BC patient seen by the PCST was analyzed to assess in which physical condition patients received the first PC consultation, which burdening symptoms they already experienced, and for how long the patients lived after their first PCST consultations. These findings were considered as indicators of how early or late in the disease trajectory patients were consulted first.

\section{Study Design}

A retrospective review of prospectively collected patient data from all BC patients seen by the PCST was performed (May 2006 to April 2008). A 1-year period was considered as adequate period of time to implement this approach and generate sufficient acceptance for the new service (PCST). Therefore, for some aspects, the data analysis was divided into 2 equal parts (first half or 'Period A': May 1, 2006 to April 30, 2007; second half or 'Period B': May 1, 2007 to April 30, 2008) to depict differences throughout the process. Generally, in the Results section, the data for the overall 2-year period are presented unless otherwise stated.

\section{PCST Infrastructure}

All consultations had to be requested by the primarily treating physicians, case managers, social workers, or nurses. The PCST was established in 2006 in addition to the interdisciplinary team of our inpatient specialized PC ward and home care service. The PCST team concept was based on the recommendations of the European Commission for the formation of
PC teams [2]. It consists of an experienced specialized PC physician (senior consultant), an experienced PC nurse and the PC case management in close cooperation with the social work, chaplaincy and psycho-oncology units. The team provides consultations in the different outpatient clinics of our center and all inpatient wards. After formation of the PCST, the team provided information about the PCST team structure and the basis PC assignments and concepts in team conferences of the different departments.

\section{Data Collection}

Consultations are requested and documented via an electronic documentation system $\left(\right.$ ORBIS $^{\circledR}$ ) and paper files. The following data were retrieved from the latter: demography, performance status score, physical symptoms, interventions performed. Routine documentation for each patient in our institution includes an assessment following the German national PC and hospice patient documentation system (Hospice and Palliative Care Evaluation, HOPE) [5]. Symptoms and problems were assessed by the staff via HOPE with an integrated symptom checklist using a 4 -point grading scale ( $0=$ none, $1=$ mild, $2=$ moderate, $3=$ severe $)$. This symptom checklist was constructed as part of the HOPE, a documentation tool for a general palliative care population, serving to document a patient's status. Detailed information on the development of the documentation tool has been published previously; HOPE has been used in several epidemiological surveys in Germany [6-8]. Documentation of symptom burden by the PCST team was compared to the assessment as reported by the patient documentation of the requesting department. The performance status score as defined by the Eastern Cooperative Oncology Group (ECOG) is used to assess physical functioning of the patients. Moreover, we compared the clinical situation as recorded on paper and in electronic files before and after PCST consultations.

\section{Data Processing}

As statistical methods we used:

- for unpaired binary-valued samples: Fisher's exact test, 95\% confidence interval $(\mathrm{CI})$ for the difference in proportions according to Newcombe's method [9]

- for paired binary-valued samples: McNemar's test, 95\% CI for the difference in proportions according to Newcombe's method

- for paired metric samples: Wilcoxon's signed rank test

- for sample proportion with a fixed value: exact binomial test Statistical significance was set at $\mathrm{p}<0.01$ (albeit uncorrected for multiple testing) [9]. Data were analyzed using R 2.9.0 software [10] and Microsoft $^{\circledR}$ Office Excel ${ }^{\circledR} 2007$.

\section{Results}

\section{Patient Population}

A total of $83 \mathrm{BC}$ patients were seen. Of these, $76(91.6 \%)$ suffered from inoperable metastases while the others $(8.4 \%)$ suffered from inoperable locally advanced disease. The number of male patients was $2(2.4 \%)$, the median age of the entire group was 61 years (range 33-84 years). Of all patients, most $(n=68 ; 82 \%)$ were seen in the department of senology, while the other consultations were requested by the radiotherapy, general surgery or internal medicine departments.

The number of new consultations increased from 29 (34.9\%) during the first to $54(65.1 \%)$ new BC patients in the second half of the observation period (CI 53.8-75.2\%; $\mathrm{p}=0.008)$. 
Table 1. Performance status (ECOG), $\mathrm{n}=83$

\begin{tabular}{|c|c|c|c|c|c|c|}
\hline ECOG & All patients, $\%(n)$ & $\mathrm{A}, \%(\mathrm{n})$ & $\mathrm{B}, \%(\mathrm{n})$ & Difference, \% & $\mathrm{CI}^{\mathrm{a}}$ & $\mathrm{p}$ Value $^{\mathrm{b}}$ \\
\hline 0 & $0.0(0)$ & $0(0.0)$ & $0(0.0)$ & 0.0 & -6.7 to $7.9 \%$ & $>0.9$ \\
\hline 1 & $15.7(13)$ & $17.2(5)$ & $14.8(8)$ & -2.4 & -21.1 to $12.8 \%$ & $>0.7$ \\
\hline 2 & $20.5(17)$ & $20.7(6)$ & $20.4(11)$ & -0.3 & -20.0 to $16.3 \%$ & $>0.9$ \\
\hline 3 & $20.5(17)$ & $13.8(4)$ & $24.1(13)$ & 10.3 & -9.0 to $25.6 \%$ & $>0.3$ \\
\hline 4 & $14.5(12)$ & $20.7(6)$ & $11.1(6)$ & -9.6 & -28.2 to $5.9 \%$ & $>0.3$ \\
\hline n.d. & $28.9(24)$ & $27.6(8)$ & $29.6(16)$ & 11.5 & -18.9 to $20.5 \%$ & $>0.9$ \\
\hline Total & $100(83)$ & $100(29)$ & $100(54)$ & & & \\
\hline \multicolumn{7}{|c|}{ 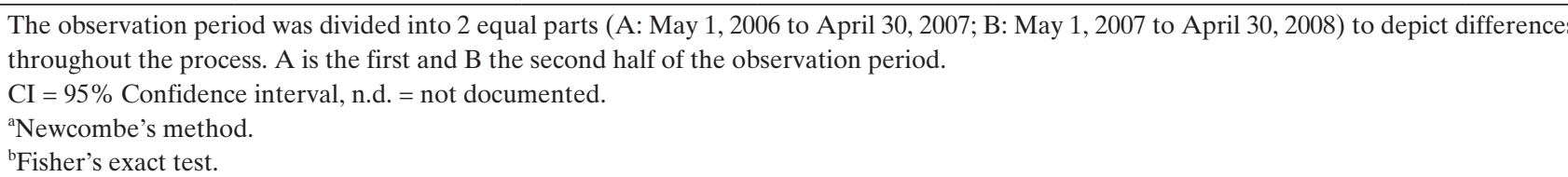 } \\
\hline
\end{tabular}

Table 2. Symptom burden at initial consultation $(\mathrm{n}=83)$

\begin{tabular}{|c|c|c|c|c|c|c|}
\hline Symptoms & All patients, \% (n) & $\mathrm{A}, \%(\mathrm{n})$ & $\mathrm{B}, \%(\mathrm{n})$ & Difference, \% & $\mathrm{CI}^{\mathrm{a}}$ & p Value ${ }^{b}$ \\
\hline Pain & $69.9(58)$ & $58.5(17)$ & $75.9(41)$ & 27.7 & $6.1-47.0 \%$ & $>0.1$ \\
\hline Weakness & $39.8(33)$ & $51.7(15)$ & $33.3(18)$ & -18.4 & -38.6 to $3.4 \%$ & $>0.1$ \\
\hline Nausea & $32.5(27)$ & $41.4(12)$ & $27.8(15)$ & -13.6 & -34.2 to $7.0 \%$ & $>0.2$ \\
\hline Fatigue or tiredness & $30.1(25)$ & $41.4(12)$ & $24.1(13)$ & -17.3 & -37.5 to $3.1 \%$ & $>0.1$ \\
\hline Anxiety & $26.5(22)$ & $34.5(10)$ & $22.2(12)$ & -12.3 & -32.6 to $7.1 \%$ & $>0.2$ \\
\hline Loss of appetite & $26.5(22)$ & $31.0(9)$ & $24.1(13)$ & -7.0 & -27.5 to $11.9 \%$ & $>0.6$ \\
\hline Constipation & $25.3(21)$ & $34.5(10)$ & $20.4(11)$ & -14.1 & -34.2 to $5.1 \%$ & $>0.1$ \\
\hline Others & $25.3(21)$ & $13.8(4)$ & $31.5(17)$ & 17.7 & -2.3 to $33.3 \%$ & $>0.1$ \\
\hline Dyspnea & $22.9(19)$ & $24.1(7)$ & $22.2(12)$ & -1.9 & -22.0 to $15.5 \%$ & $>0.9$ \\
\hline Social issues & $15.7(13)$ & $27.6(8)$ & $9.3(5)$ & -18.3 & -37.2 to $-1.6 \%$ & 0.054 \\
\hline Depression & $19.3(16)$ & $27.6(8)$ & $14.8(8)$ & -12.8 & -32.2 to $4.7 \%$ & $>0.2$ \\
\hline
\end{tabular}

The observation period was divided into 2 equal parts (A: May 1, 2006 to April 30, 2007; B: May 1, 2007 to April 30, 2008 ) to depict differences throughout the process. A is the first and B the second half of the observation period.

n does not sum up to 83 since patients often suffered from multiple symptoms.

$\mathrm{CI}=95 \%$ Confidence interval.

aNewcombe's method.

b'Fisher's exact test.

\section{PC Integration: Early or Late in the Disease Trajectory?}

As indicators for the timing of PC integration, we analyzed (i) performance status and (ii) symptoms as markers for advanced disease (e.g. dyspnea) [3, 4]. About every second patient was already in a considerably decreased physical state (ECOG 3 and 4) (table 1). When comparing the 1 st to the 2 nd year, this did not change significantly, although a tendency towards fewer patients with ECOG 4 was seen.

The prevalence of pain, dyspnea and other burdening symptoms did not decrease significantly after a 1-year period (table 2). Likewise, the overall prevalence of symptoms per patient decreased non-significantly from 5.0 to 3.0 $(\mathrm{p}=0.3037)$.

\section{Other PC Issues}

Patients received counselling by the PCST for a median of 7 days (range 1-239 days). 28 patients (34\%) were seen for a period of less than 3 days, 57 patients (69\%) were seen for less than 1 month (31 days) and 8 (10\%) for more than 3 months.

Most PC consultations were specifically requested for symptom control $(n=80 ; 96 \%)$. Of these, $53(64 \%)$ concerned pain management.

The number of cancer pain patients receiving opioid rescue medication increased significantly from $10(12.0 \%)$ to 45 (54.2\%) after PC consultation (difference $42.2 \%$; CI 28.9 $53.4 \% ; \mathrm{p}<0.0001)$. Such a significant increase could also be demonstrated for cancer pain patients who were receiving 
Table 3. Development of requests and interventions not regarding symptom control $(\mathrm{n}=83)$

\begin{tabular}{|c|c|c|c|c|c|}
\hline & $\mathrm{A}, \%(\mathrm{n})$ & $\mathrm{B}, \%(\mathrm{n})$ & Difference, \% & $\mathrm{CI}$ & $\mathrm{p}$ Value \\
\hline Number of patients & $34.9(29)$ & $65.1(54)$ & 30.1 & $53.8-75.2 \%{ }^{a}$ & $0.008^{\mathrm{a}}$ \\
\hline $\begin{array}{l}\text { Social or communicative intervention specifically } \\
\text { requested }\end{array}$ & $13.8(4)$ & $20.4(11)$ & $6.6 \%$ & -12.3 to $21.6 \%^{\mathrm{b}}$ & $>0.5^{\mathrm{c}}$ \\
\hline Admission to palliative care ward requested & $13.8(4)$ & $3.7(2)$ & -10.1 & -27.1 to $2.0 \%{ }^{\mathrm{b}}$ & $>0.1^{\mathrm{c}}$ \\
\hline Social or communicative intervention performed & $69.0(20)$ & $57.4(31)$ & -11.6 & -30.7 to $10.4 \%{ }^{b}$ & $>0.3^{\mathrm{c}}$ \\
\hline
\end{tabular}

The observation period was divided into 2 equal parts (A: May 1, 2006 to April 30, 2007; B: May 1, 2007 to April 30, 2008) to depict differences throughout the process. A is the first and B the second half of the observation period.

$\mathrm{CI}=95 \%$ Confidence interval.

${ }^{\mathrm{a}}$ Exact binomial test, CI for observational period B.

bNewcombe's method.

'Fisher's exact test.

strong opioids (WHO III). This number increased from 25 (30.1\%) to 47 (56.6\%) (difference 26.5\%; CI 16.4-35.6\%; $\mathrm{p}<0.0001)$.

Of all patients, 19 patients $(22.9 \%)$ suffered from dyspnea. 4 of these patients $(21.1 \%)$ received WHO III opioid medication prior to consultation. This number rose significantly to 12 of the 19 patients (63.2\%) (difference $42.1 \%$; CI $15.1-$ $60.9 \% ; p=0.013)$ after consultation. Only $1(5.3 \%)$ of the dyspnea patients received a WHO III rescue medication before consultation, increasing 9-fold to $9(47.4 \%)$ afterwards (difference 42.1\%; CI 14.4-63.4\%; $\mathrm{p}=0.013$ ).

In the second half of the observation period, non-PC physicians increasingly requested PC support for social or communicative interventions (from $13.8 \%(\mathrm{n}=4)$ to $20.4 \%(\mathrm{n}=$ 11); difference $6.6 \%$; CI $-12.3-21.6 \% ; \mathrm{p}=0.559$ ) (table 3).

Apart from measures concerning symptom control, PC interventions resulted in clarification of social or communicative issues $(\mathrm{n}=51 ; 62 \%)$ and assessment of the indication for admittance to the PC ward $(\mathrm{n}=16 ; 19 \%)$. Psychosocial interventions that had to be conducted by the support team were thorough and detailed explanations of the different aspects and options of PC $(\mathrm{n}=40 ; 48 \%)$, structured conversations with relatives ('physician-family rounds') $(\mathrm{n}=13 ; 15.7 \%)$, and coordination of social work $(n=9 ; 10.9 \%)$.

\section{Discussion}

\section{PC Needs of BC Patients}

In our patient population, a large number of patients suffered from severe symptoms and psychosocial issues. The identification and treatment of burdensome symptoms increased dramatically after PC consultation. This is in line with the findings of other authors who demonstrated that $\mathrm{BC}$ patients experience physical and emotional distress $[11,12]$ and that the integration of a PCST is helpful in providing adequate symptom control and psychosocial support [13-16].

\section{Recommending Early Integration of PC as Standard of Cancer Care}

It has currently become increasingly accepted that the early integration of PC competencies into the treatment of patients with life-limiting diseases increases somatic, social and spiritual well-being ('quality of life') [17-23]. Specifically, the WHO recommends integrating PC expertise from the time of diagnosis of a life-limiting disease [1]. Because this recommendation is lacking any further information as to how this can be achieved, different approaches have been published. Other centers tried to facilitate the integration of PC into cancer therapy by establishing clinical trials [24], 'nursing-led psychoeducational intervention teams' [25], PCSTs as the sole providers of PC support [26] or a combination of both inpatient wards, home care and PCST [13, 27]. In our own institution, we decided to adopt the WHO recommendations into the administrative directives of our institution's principles of cancer care as a means to promote that non-PC clinicians implement PC early in the course of (breast) cancer therapy $[1,17]$. Furthermore, it was decided to provide a multi-professional PCST (PC nurse and specialized PC physician) as recommended by the European Commission [2] in addition to a pre-existing specialized inpatient PC ward and home care service. The PCST was assigned to conduct consultations for both in- and outpatients during the pilot project. The additional provision of a specialized inpatient PC ward was necessary for a large proportion of the patients for whom PCST consultations alone did not suffice $[15,28]$.

\section{Developing a 'PC Culture'?}

Comparing the findings of the 1st to the 2nd year of this approach, 2 findings of this study might be interpreted as an increasing acceptance of the 'early integration' concept during the course of time.

- Over time, PC support was requested more specifically for psychosocial or communicative interventions, and not only for symptom control. However, it is only an assumption 
that this could display a development towards a better understanding of PC assignments whereas PC might have been misinterpreted as mere 'symptomatology' by clinicians who were lacking PC expertise before the beginning of this project [29, 30].

- Over time, there was a significant increase in referrals to the PCST team. As Bruera et al. [31, 32] describe a necessary 'evolutionary process' for a 'PC culture' when implementing PC programs, this result may be interpreted as growing acceptance of the early integration approach.

\section{'Early Integration of PC' - an Unmet Standard of Care?}

Despite the promising developments described above, the provision of PC early in the disease trajectory failed. Many patients were already in a reduced physical state and often suffered from symptoms experienced rather late in the disease trajectory (e.g. dyspnea). These findings did not change significantly after the 1 st year of the project. This supports the perception of the members of our PCST that the mere recommendation of providing PC 'early' in the disease trajectory is too vague to overcome well-known barriers towards such an approach. Many of these barriers actually concern the misperception of PC by other physicians [33]. PC is often mistaken as 'terminal care' by non-PC physicians [34]. Other professionals are afraid of 'discouraging' the patients when requesting a PC consultation [19]. Therefore, the ambiguity of the WHO recommendation might not be specific enough to trigger $\mathrm{PC}$ integration as the decision on when to integrate $\mathrm{PC}$ remains highly dependent on the primarily treating physician [28]. The negative consequences for holistic and patient-centered cancer therapy have been studied earlier $[33,35]$.

\section{Specifying the WHO Recommendations}

Reflecting on these findings, we concluded that the WHO recommendation is too vague to serve as a clinical guideline. Specifically, since health care professionals often feel uncomfortable in determining the point of the disease trajectory at which 'early' integration is desirable, the identification of 'green flags' is considered as helpful. As one approach to overcome this barrier, the National Comprehensive Cancer Network (NCCN) published guidelines for PC implementation [36]. These guidelines focus on both expected survival time or symptom burden as triggers (green flags) to initiate PC integration, but the NCCN itself has addressed the difficulty of successfully integrating guidelines into everyday practice [37].

The correct identification of expected survival time for a specific patient is often problematic and using only symptom burden as a trigger for PC integration may lead to (too) late referrals. The comparison to findings assessing PC implementation into lung cancer therapy $[38,39]$ suggest that, due to differences in the disease trajectory and in the needs of patients suffering from different malignancies, the development of disease-specific standard operating procedures (SOPs) could be helpful to facilitate the provision of PC according to the patients' needs. Such guidelines would provide diseaseand stage-specific points to institutionalize and ensure early integration of PC. Meanwhile, these disease-specific SOPs have been developed for 24 hemato-oncological diseases and will be presented elsewhere, such as the one for lung cancer $[38,39]$.

\section{Limitations of the Study}

Because of the study design, we are unable to provide data about patients who were not receiving PC support. Therefore, the difference in symptom burden between these 2 groups of patients cannot be evaluated. A randomized prospective trial is planned to address this question.

\section{Conclusions}

Comparing these results to the assessment of patients with lung cancer [38, 39], it becomes evident that disease-specific guidelines are necessary to facilitate and optimize the integration of PC into cancer therapy, since the WHO recommendations are too vague to serve as a general clinical guideline. As a consequence, in addition to inclusion in administrative directives and establishment of a PCST, we recommend the development of SOPs. These are supposed to act as diseasespecific guidelines to define disease-specific points in the disease trajectory at which PC should be integrated into the clinical pathway. Yet, beyond SOPs, future developments should also focus on (i) implementing PC as a mandatory component of (breast) cancer therapy, (ii) ensuring that, beyond the mere provision of guidelines, $\mathrm{PC}$ attitude and culture become an integral part of patient care, and (iii) keeping palliative care as a holistic attitude and approach that cannot be broken down into simple treatment algorithms.

\section{Acknowledgements}

The clinical and scientific work of the Department of Palliative Medicine is substantially supported by the German Cancer Aid (Deutsche Krebshilfe e.V.). The scientific work is funded by the Federal Ministry of Education and Research (BMBF01KN0706).

\section{Disclosure Statement}

The authors declare no conflict of interest. 


\section{References}

1 WHO: National Cancer Control Programmes Policies and Managerial Guidelines, ed 2. Geneva, WHO, 2002.

2 European Commission: Promoting the development and integration of palliative care mobile support teams in the hospital - The Fifth Framework Programme 1998-2002 'Quality of Life and Management of Living Resources'. Brussels, EC, 2003.

3 Buckholz GT, von Gunten CF: Nonpharmacological management of dyspnea. Curr Opin Support Palliat Care 2009;3:98-102.

4 Lutz S, Norrell R, Bertucio C, Kachnic L, et al.: Symptom frequency and severity in patients with metastatic or locally recurrent lung cancer: a prospective study using the lung cancer symptom scale in a community hospital. J Palliat Med 2001;4:157165

$\checkmark 5$ Radbruch L, Ostgathe C, Elsner F, Nauck F, Bausewein C, Fuchs M, Lindena G, Neuwöhner K, Schulenberg D: [What is the profile of palliative care in Germany. Results of a representative survey]. Schmerz 2004;18:179-188.

6 Radbruch L, Nauck F, Ostgathe C, Elsner F, et al. What are the problems in palliative care? Results from a representative survey. Support Care Cancer 2003;11:442-451.

7 Nauck F, Ostgathe C, Klaschik E, Bausewein $\mathrm{C}$, et al.: Drugs in palliative care: results from a representative survey in Germany. Palliat Med 2004;18:100-107.

8 Ostgathe C, Gaertner J, Kotterba M, Klein S, Lindena $\mathrm{G}$, et al.: Differential palliative care issues in patients with primary and secondary brain tumours. Support Care Cancer 2010;18:1157-1163.

9 Altman DG, Machin D, Bryant T, et al.: Statistics with Confidence: Confidence Intervals and Statistical Guidelines. London, BMJ Books, 2000, pp 50-54.

10 Development Core Team: A Language and Environment for Statistical Computing. Vienna, R Foundation for Statistical Computing, 2009.

-11 Chunlestskul K, Carlson LE, Koopmans JP, Angen M: Lived experiences of Canadian women with metastatic breast cancer in preparation for their death: a qualitative study. Part II. Enabling and in hibiting factors; the paradox of death preparation. J Palliat Care 2008;24:16-25.
Harbeck N, Haidinger R: The patient experience. Breast Cancer Res Treat 2007;105(suppl 1):91-103.

13 Fadul N, Elsayem A, Palmer JL, Zhang T, et al.: Predictors of access to palliative care services among patients who died at a comprehensive cancer center. J Palliat Med 2007;10:1146-1152.

14 Ciemins EL, Blum L, Nunley M, Lasher A, et al.: The economic and clinical impact of an inpatient palliative care consultation service: a multifaceted approach. J Palliat Med 2007;10:1347-1355.

15 Dhillon N, Kopetz S, Pei BL, Fabbro ED, Zhang T, et al.: Clinical findings of a palliative care consultation team at a comprehensive cancer center. J Palliat Med 2008;11:191-197.

16 Osta BE, Palmer JL, Paraskevopoulos T, Pei BL, Roberts LE, et al.: Interval between first palliative care consult and death in patients diagnosed with advanced cancer at a comprehensive cancer center. J Palliat Med 2008;11:51-57.

17 Ferris FD, Bruera E, Cherny N, Cummings C, et al.: Palliative cancer care a decade later: accomplishments, the need, next steps - from the American Society of Clinical Oncology. J Clin Oncol 2009;27:3052-3058.

18 Grant M, Elk R, Ferrell B, Morrison RS, von Gunten CF: Current status of palliative care - clinical implementation, education, and research. CA Cancer J Clin 2009;59:327-335.

19 Wright AA, Zhang B, Ray A, Mack JW, Trice E, et al.: Associations between end-of-life discussions, patient mental health, medical care near death, and caregiver bereavement adjustment. JAMA 2008;300:1665-1673.

20 Zhang B, Wright AA, Huskamp HA, Nilsson ME, et al.: Health care costs in the last week of life: associations with end-of-life conversations. Arch Intern Med 2009:169:480-488.

21 Periyakoil VS, von Gunten CF: Mainstreaming palliative care. J Palliat Med 2007:10:40-42.

22 von Gunten CF: Palliative medicine. Impact. J Palliat Med 2008;11:536-537.

23 Schapira L, Moynihan TJ, von Gunten CF, Smith TJ: Phase I versus palliative care: striking the right balance. J Clin Oncol 2009;27:307-308.

24 Temel JS, Jackson VA, Billings JA, Dahlin C, Block SD, et al.: Phase II study: integrated palliative care in newly diagnosed advanced nonsmall-cell lung cancer patients. J Clin Oncol 2007:25:2377-2382.
5 Bakitas M, Lyons KD, Hegel MT, Balan S, Brokaw FC, et al.: Effects of a palliative care intervention on clinical outcomes in patients with advanced cancer: the Project ENABLE II randomized controlled trial. JAMA 2009;302:741-749.

26 Higginson IJ: End-of-life care: lessons from other nations. J Palliat Med 2005;8(suppl 1):S161-S173.

27 Elsayem A, Smith ML, Parmley L, Palmer JL, et al.: Impact of a palliative care service on in-hospital mortality in a comprehensive cancer center. J Palliat Med 2006;9:894-902.

28 Snow CE, Varela BR, Pardi DA, Adelman RD, et al.: Identifying factors affecting utilization of an inpatient palliative care service: a physician survey. J Palliat Med 2009;12:231-237.

29 Twycross RG: The challenge of palliative care. Int J Clin Oncol 2002;7:271-278.

30 Voltz R: [Symptomatology or palliative medicine?]. Palliativmedizin 2009;9:197-198.

31 Bruera E, Periyakoil VS: On third base but not home yet. J Palliat Med 2008;11:565-569.

32 Bruera E: The development of a palliative care culture. J Palliat Care 2004;20:316-319.

33 von Gunten CF: Who uses palliative care? J Palliat Med 2009;12:209.

34 Fadul N, Elsayem A, Palmer JL, Del Fabbro E, et al.: Supportive versus palliative care: what's in a name? A survey of medical oncologists and midlevel providers at a comprehensive cancer center. Cancer 2009;115:2013-2021.

35 Von Roenn JH, von Gunten CF: Are we putting the cart before the horse? Arch Intern Med 2009;169:429.

36 Levy MH, Back A, Benedetti C, Billings JA, Block $\mathrm{S}$, et al.: NCCN clinical practice guidelines in oncology: palliative care. J Natl Compr Cancer Netw 2009;7:436-473.

37 McNeil C: Can guidelines be integrated into everyday practice? The NCCN in year 4. National Comprehensive Cancer Network [news]. J Natl Cancer Inst 1999;91:753-755.

38 Gaertner J, Wolf J, Scheicht D, Frechen S, Klein $\mathrm{U}$, et al: Implementing WHO recommendation for palliative care into routine lung cancer therapy - a feasibility study. J Palliat Med 2010;13:727-732.

39 Gaertner J, Wolf J, Ostgathe C, Toepelt K, et al.: Specifying WHO recommendation - moving towards disease specific guidelines. J Palliat Med 2010;13:1273-1276. 